\title{
A study to Assess the Knowledge Regarding Human Right of Mentally III Patient among Community People in Kaski, Pokhara,Nepal
}

\author{
Koirala $\mathbf{D}^{1^{*}}$, Silwal $\mathbf{M}^{2}$, Gurung $\mathbf{A}^{1}$, Gurung $\mathbf{R}^{1}$, Sah $\mathbf{I}^{1}$, Paudel $\mathbf{S}^{1}$ \\ 'Lecturer, ${ }^{2} \mathrm{Co}$-ordinator, \\ College of Nursing Sciences, Gandaki Medical College, Pokhara, Nepal
}

\begin{abstract}
Introduction: Mental health problems raise many human rights issues. People with mental illness are exposed to human rights violation within and outside the health care context. Because of lack of awareness, people with mental illness and their families do not exercise their rights. Psychiatric patients are most vulnerable groups in community. Incidence of violation of rights of mentally ill patients can be avoided if the community people become aware of them.
\end{abstract}

Objective: To assess knowledge regarding human rights and myth of mental illness among community people.

Method: A descriptive crosssectional study was conducted among 140 community people of Ritthepani-27, Kaski, Nepal. Non probability convenient sampling technique was adopted to collect the data. Inclusion criteria included head of the family of the selected community who were willing to participate in the study. Data was collected through face to face interview using a structured questionnaire.

Results: In the present study, it was found that $46.40 \%$ of the community people had inadequate knowledge regarding human rights of mentally ill patients. There was no significant association between demographic variables and knowledge score of the respondents. The study found that

\section{Keywords}

Community, Human rights, Mentally ill, Knowledge, Myth.

\section{Corresponding Author}

*Ms Dipti Koirala

Lecturer, College of Nursing Sciences

Gandaki Medical College, Pokhara, Nepal

Email: diptibanjara@yahoo.com more than half of the respondents (51\%) had belief that mental illness is not related to physical health. Likewise $36.4 \%$ believed mental illness is caused by supernatural power and evil and $30 \%$ believed that marriage can cure mental illness.

Conclusion: Based on findings, it is concluded that the level of knowledge regarding rights of mentally ill patient is inadequate and there is a high prevalence of myths and misconceptions related to mental illness among the adult population. So, there is need to conduct awareness raising activities in the community.

\section{INTRODUCTION}

Mental, physical and social health are vital strands of life that are closely interwoven and deeply interdependent. Mental health is crucial to the overall wellbeing of individuals, societies and countries. ${ }^{1} \mathrm{~A}$ healthy person has a fit physique, satisfying social status, balanced emotional health along with sound mental health. These all dimensions are closely related and directly affect each other. A person who is able to understand the facts, rationalize the doubts, interpret the views and solves the problem tactfully is considered mentally healthy but 
a person who has clinically significant disturbance in cognition, emotion regulation or behavior that reflects a dysfunction in the psychological, biological and developmental processes underlying mental functioning is considered as a mentally ill. Hence, mental illness refers to a wide range of mental health conditions disorders that affect the mood, thinking and behaviour. ${ }^{2}$

WHO says one in four people in the world will be affected by mental or neurological disorders at some point in their lives and around 450 million people currently suffer from such conditions, placing mental disorders among the leading causes of ill-health and disability worldwide. Despite of the availability of treatments nearly two-thirds of people with a known mental disorder never seek help from a health professional due to stigma, discrimination and negligence. ${ }^{1}$ Many people have mental health concerns from time to time. But a mental health concern becomes a mental illness when ongoing signs and symptoms cause frequent stress and affect the ability to function effectively and efficiently. ${ }^{3}$

Community is a place surrounded with people of different thoughts, beliefs and concepts. Therefore, people in a community have different widespread stigmatizations of mental illnesses. Decades of research have established that the public holds negative beliefs about persons with mental illnesses among them that such individuals are dangerous, unpredictable, unattractive, and unworthy and are unlikely to be productive members of their communities. Moreover, these negative perceptions and stigmas have been remarkably constant despite advances in scientific understanding of mental illnesses and extensive efforts to improve public understanding. ${ }^{4}$

Hence, mental illness is difficult to understand and can lead to prejudice and discrimination. So, it is the utmost need of today that people should know, understand and accept mental illness as it is the most effective way of battling stigma towards those diagnosed with mental illness. This understanding provides an environment where a mentally healthy person can provide compassion and empathization towards the affected by strengthening the relationship in increasing the understanding among one another. ${ }^{5}$ Thus, this study intended to get the baseline data on knowledge about rights of mentally ill patients and myths on mental illness.

\section{Objectives of the study}

- To assess the level of knowledge of community people regarding human rights of mentally ill patient.

- To determine the knowledge of community people on myths regarding mental illness.

- To find association of level of knowledge regarding human rights of mentally ill patient with selected variables.

\section{METHODS}

A descriptive cross-sectional research design was used to conduct the study among 140 community people residing in Ward no 27 of Pokhara Municipality of Kaski district, Nepal. Five toles of ward 27 namely Shiva tole, Milan tole, Sundari tole, Sworga tole and Durga tole were purposively selected and then 28 people meeting the criteria were selected from each toles on first come first basis by visiting house to house using convenient sampling technique. Sample included the head of the family of the selected community who were available during the period of data collection. Only one member of each household (older one) was included in the study.

A semi-structured interview schedule was developed through review of related literature and consultation to the experts which was organized into three parts: Part I consisted of semi-structured questions related to sociodemographic characteristics which included age, gender, education, occupation, ethnicity and religion. Part II consisted of structured questions related to 14 human rights of mentally ill patient and Part III consisted of 13 myths related to mental illness. ${ }^{3,6}$

The scoring of part II of the questionnaire were determined by giving one point (1) for each correct response and zero (0) for wrong answers or no response. The total knowledge score were calculated by adding up the scores for each question in the test. The total knowledge scores ranged from zero to 14, with higher scores indicating a higher level of knowledge. According to the median split method, ${ }^{7}$ respondents with a total score of less than median were considered as having inadequate knowledge regarding human rights of mentally ill and those with scores median and above were considered as having adequate knowledge. This scoring method and categorization was used to identify the level of respondents' knowledge in the current study.

Overall, validity of the instrument was ascertained by 
reviewing the related literatures and consultation with peers, research advisors and subject matter experts before and during the construction of the tool. To identify accuracy, clarity and consistency of the tool, pretesting of the instrument was conducted on 14 people meeting the criteria in Lamtara tole of the ward no 27 of Lekhnath municipality.

Data was collected by researchers themselves with the help of B.Sc. nursing students from June 29, 2017 to July 22, 2017 (2074/3/15 to 2074/4/7 B.S) after obtaining verbal permission from the chairperson of the ward. Data was collected at the place convenient for respondents in their residence by face to face interview schedule. Respondents were approached in the daytime as they were busy with work during morning and evening time. Informed verbal and written consent was obtained from the respondents prior to data collection after giving information about the nature of the study and their role in research. To maintain the quality of the data, clear instruction was given about answering the questionnaire. The average time taken for the questionnaire was about 20-30 minutes. About 7-8 respondents were interviewed in a day. After the data collection, every queries of respondents were addressed and informal health teaching regarding rights and myths of mentally ill patient was provided.

The data were coded and entered in IBM Statistical Package for Social Sciences (IBMSPSS, version 20). Data was analyzed and interpreted by using descriptive statistics (frequency, percentage, mean, median and standard deviation) to describe the socio demographic as well as the knowledge and myths related variables and inferential statistics (Chi-square test) was used to measure association of level of knowledge about rights of mentally ill patient with selected variables. The level of significance was set at less than 0.05 for all analyses.

\section{RESULTS}

Table 1: Frequency and percentage distribution of demographic characteristics $(n=140)$

\begin{tabular}{|ccc|}
\hline Characteristics & Frequency & Percentage (\%) \\
\hline Age in years & & \\
$-\quad \leq 40$ & 102 & $72.9 \%$ \\
$-\quad>40$ & 38 & $27.1 \%$ \\
\hline
\end{tabular}

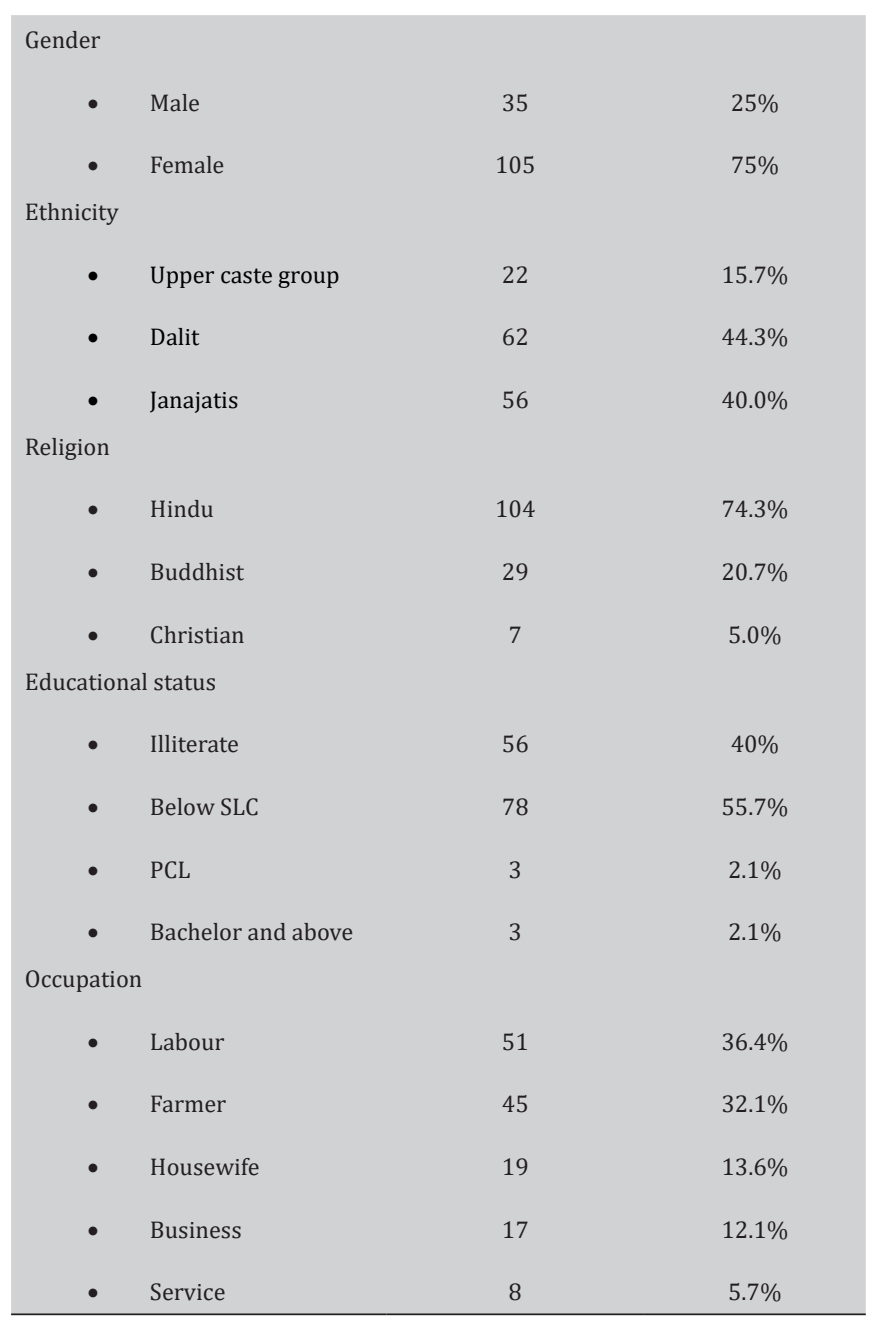

Table 1 shows that out of 140 respondents, 102 (72.9\%) were below 40 years of age, three fourth (75\%) were females, 62 (44.3\%) belonged to Dalit group, 104 (88.7\%) were Hindus by religion, $84(60 \%)$ were literate and 51 (36.4\%) were labor workers.

Table 2: Knowledge of community people on rights of mentally ill patient $(n=140)$

\begin{tabular}{|c|c|c|}
\hline Rights & Frequency & Percentage \\
\hline \multicolumn{3}{|c|}{ Right to treatment in least restrictive method } \\
\hline Yes & 37 & $26.4 \%$ \\
\hline No & 103 & $73.6 \%$ \\
\hline \multicolumn{3}{|c|}{ Right to confidentiality of records } \\
\hline Yes & 97 & $69.3 \%$ \\
\hline No & 43 & $30.7 \%$ \\
\hline \multicolumn{3}{|c|}{$\begin{array}{l}\text { Right to freedom from restraints and } \\
\text { seclusion }\end{array}$} \\
\hline Yes & 106 & $75.7 \%$ \\
\hline No & 34 & $24.3 \%$ \\
\hline \multicolumn{3}{|c|}{$\begin{array}{l}\text { Right to give or refuse consent to treat- } \\
\text { ment }\end{array}$} \\
\hline Yes & 106 & $75.7 \%$ \\
\hline
\end{tabular}




\begin{tabular}{|c|c|c|}
\hline No & 34 & $24.3 \%$ \\
\hline \multicolumn{3}{|c|}{ Right to access to personal belongings } \\
\hline Yes & 123 & $87.9 \%$ \\
\hline No & 17 & $12.1 \%$ \\
\hline \multicolumn{3}{|l|}{ Right to daily exercise } \\
\hline Yes & 121 & $86.4 \%$ \\
\hline No & 19 & $13.6 \%$ \\
\hline \multicolumn{3}{|l|}{ Right to have visitors } \\
\hline Yes & 120 & $85.7 \%$ \\
\hline No & 20 & $14.3 \%$ \\
\hline \multicolumn{3}{|c|}{$\begin{array}{l}\text { Right to use of writing materials and } \\
\text { uncensored mails }\end{array}$} \\
\hline Yes & 90 & $64.3 \%$ \\
\hline No & 50 & $35.7 \%$ \\
\hline \multicolumn{3}{|l|}{ Right to use of telephone } \\
\hline Yes & 85 & $60.7 \%$ \\
\hline No & 55 & $39.3 \%$ \\
\hline \multicolumn{3}{|c|}{ Right to access courts and attorney } \\
\hline Yes & 70 & $50 \%$ \\
\hline No & 70 & $50 \%$ \\
\hline \multicolumn{3}{|c|}{ Right to employment compensation } \\
\hline Yes & 92 & $65.7 \%$ \\
\hline No & 48 & $34.3 \%$ \\
\hline \multicolumn{3}{|c|}{ Right to be informed of rights } \\
\hline Yes & 130 & $92.9 \%$ \\
\hline No & 10 & $7.1 \%$ \\
\hline \multicolumn{3}{|c|}{ Right to wear their own clothes } \\
\hline Yes & 131 & $93.6 \%$ \\
\hline No & 9 & $6.4 \%$ \\
\hline \multicolumn{3}{|c|}{$\begin{array}{l}\text { Right to spend a sum of their money for } \\
\text { their own expenses }\end{array}$} \\
\hline Yes & 102 & $72.9 \%$ \\
\hline No & 38 & $27.1 \%$ \\
\hline
\end{tabular}

Table 2 presents the knowledge of community people on rights of mentally ill patient which shows that patient's right to get treatment in least restrictive method was not known by about three fourth (73.6\%) of the respondents. Half of the respondents were not aware that mentally ill have right to access courts and attorney.

Table 3: Statistics of overall scoring on level of knowledge $(n=140)$

\begin{tabular}{cccccc}
\hline Variable & $\begin{array}{c}\text { Total } \\
\text { Possible } \\
\text { Score }\end{array}$ & Mean & Median & $\begin{array}{c}\text { Mini- } \\
\text { mum }\end{array}$ & $\begin{array}{c}\text { Maxi- } \\
\text { mum }\end{array}$ \\
\hline $\begin{array}{c}\text { Overall knowledge } \\
\text { score on rights of } \\
\text { mentally ill }\end{array}$ & 14 & 10.54 & 11.00 & 2 & 14 \\
\hline $\begin{array}{c}\text { Percentage of knowl- } \\
\text { edge score on rights } \\
\text { of mentally ill }\end{array}$ & $100 \%$ & $(2.17)$ & & & \\
\hline
\end{tabular}

Table 3 reveals the statistics of overall scoring of the respondents level of knowledge regarding rights of mentally ill patients. It shows that 14 was full score that could be obtained and the maximum score obtained by the respondent was 14 (100\%) and minimum score was $2(14.28 \%)$. The table also shows the mean score was 10.54 and $75.28 \%$ and standard deviation was 2.17 and $15.5 \%$. The Median score was 11 and $78.57 \%$.

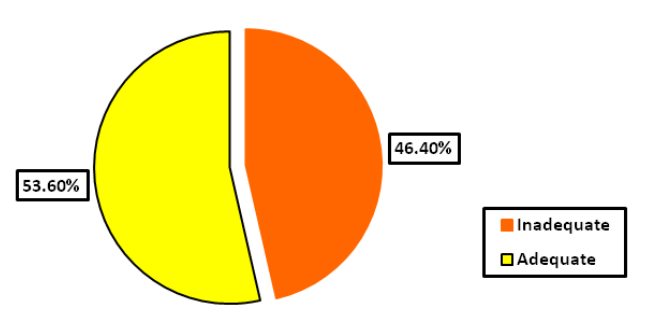

Fig 1: Level of knowledge of community people on rights of mentally ill patient $(n=140)$

Figure 1 illustrates the level of knowledge of the respondents about the rights of mentally ill patient which shows that among 140 respondents, 65 people (46.4\%) have inadequate knowledge regarding human rights of mentally ill patients.

Table 4: Knowledge of community people on myths regarding mental illness $(\mathrm{n}=140)$

\begin{tabular}{|c|c|c|}
\hline Myths & Frequency & Percentage \\
\hline \multicolumn{3}{|c|}{ Belief that mental health is not related to physical health } \\
\hline Yes & 72 & $51.4 \%$ \\
\hline No & 68 & $48.6 \%$ \\
\hline \multicolumn{3}{|c|}{$\begin{array}{l}\text { Belief that mental illness is caused by supernatural power and is the result of } \\
\text { a curse by evil spirit }\end{array}$} \\
\hline Yes & 51 & $36.4 \%$ \\
\hline No & 89 & $63.6 \%$ \\
\hline \multicolumn{3}{|c|}{ Belief that marriage can cure mental illness } \\
\hline Yes & 42 & $30 \%$ \\
\hline No & 98 & $70 \%$ \\
\hline \multicolumn{3}{|c|}{$\begin{array}{l}\text { Belief that prevalence of mental illness are low } \\
\text { in our country }\end{array}$} \\
\hline Yes & 108 & $77.1 \%$ \\
\hline No & 32 & $22.9 \%$ \\
\hline \multicolumn{3}{|c|}{$\begin{array}{l}\text { Belief that mental illness once acquired is life } \\
\text { long }\end{array}$} \\
\hline Yes & 58 & $41.4 \%$ \\
\hline No & 82 & $58.6 \%$ \\
\hline \multicolumn{3}{|c|}{$\begin{array}{l}\text { Belief that the only place for the mentally ill is } \\
\text { an asylum }\end{array}$} \\
\hline Yes & 69 & $49.3 \%$ \\
\hline No & 71 & $50.7 \%$ \\
\hline Belief that no effective treatr & & \\
\hline
\end{tabular}




\begin{tabular}{lccc} 
& Yes & 63 & $45 \%$ \\
& No & 77 & $55 \%$ \\
$\begin{array}{l}\text { Belief that mental disorders are something } \\
\text { ashamed }\end{array}$ & & \\
& Yes & 89 & $63.6 \%$ \\
& No & 51 & $36.4 \%$ \\
\hline
\end{tabular}

Table 4 shows that the myth of community people towards mental illness is very high. More than three fourth $(77.1 \%)$ of the respondents believed that there is low prevalence of mental illness in our country. More than half of the respondents i.e. $63.6 \%$ and $51 \%$ believed that mental disorders are shameful and mental illness is not related to physical health respectively. Likewise, $36.4 \%$ of the people believed mental illness is caused by supernatural power and evil. Similarly $30 \%$ of the respondents believed that marriage can cure mental illness, with $41.4 \%$ believed mental illness as life-long problem and $45 \%$ believed that no effective treatment is available for mental illness.

Table 5: Association of level of knowledge about rights of mentally ill patient with selected variables $(n=140)$

\begin{tabular}{lcccc}
\hline \multicolumn{1}{c}{ Variables } & \multicolumn{2}{c}{ Level of Knowledge } & & \\
\cline { 2 - 3 } & $\begin{array}{c}\text { Inade- } \\
\text { quate No. } \\
\text { (\%) }\end{array}$ & $\begin{array}{c}\text { Adequate No. } \\
\text { (\%) }\end{array}$ & $\chi^{2}$ & p- value \\
\hline Age (in years) & & & & \\
$\leq 40$ & $44(43.1)$ & $58(56.9)$ & 1.637 & 0.201 \\
$>40$ & $21(55.3)$ & $17(44.7)$ & & \\
Gender & & & & \\
Male & $19(54.3)$ & $16(45.7)$ & 1.158 & 0.282 \\
Female & $46(43.8)$ & $59(56.2)$ & & \\
Education & & & & \\
Illiterate & $29(51.8)$ & $27(48.2)$ & 1.077 & 0.299 \\
Literate & $36(42.9)$ & $48(57.1)$ & & \\
Religion & & & & \\
Hindu & $45(43.3)$ & $59(56.7)$ & 1.623 & 0.203 \\
Others & $20(55.6)$ & $16(44.4)$ & & \\
Occupation & & & & \\
Working & $36(49.3)$ & $37(50.7)$ & .511 & 0.475 \\
Non working & $29(43.3)$ & $38(56.7)$ & & \\
Ethnicity & & & & \\
Dalit & $29(46.8)$ & $33(53.2)$ & 0.005 & \\
Non dalit & $36(46.2)$ & $42(53.8)$ & & \\
\hline Significant & & & \\
\hline
\end{tabular}

Significant level of P-value at 0.05

Table 5 shows association between respondents' level of knowledge regarding rights of mentally ill patient and socio-demographic characteristics. There was no statistically significant association of respondents' level of knowledge with the demographic variables: age, gender, education, religion, occupation and ethnicity.

\section{DISCUSSION}

The present study assessed the knowledge of community people towards right of mentally ill people. The finding revealed that out of 140 respondents, 102 (72.9\%) were below 40 years of age, three fourth $(75 \%)$ were female, 62 (44.3\%) belonged to Dalit group, 104 (88.7\%) were Hindus by religion, 84 (60\%) were literate and 51 (36.4\%) were labor workers.

The finding of the study revealed that around half of the respondents (46.40\%) had inadequate knowledge about right of mentally ill people. This finding was consistent with the other study which revealed that $56.7 \%$ had inadequate knowledge on right of the mentally people 8 . Another study also showed that $68 \%$ of adults have poor knowledge and $24 \%$ have average knowledge about the rights of mentally ill people. ${ }^{9}$

The current study showed no statistically significant association between the knowledge score of community people and demographic variables like age, gender, ethnicity, religion, education and occupation. This finding is consistent with the finding of the study conducted by Chendake et $\mathrm{al}^{10}$ in 2014. Moreover, another study also showed no statistical significant association between knowledge of adults and age, sex, religion and monthly income. However, knowledge of adults was related to the type of family, no. of family members and educational status. $^{9}$

The present found a high prevalence of myths related to mental illness with almost all i.e. $98.6 \%$ people believing that mentally ill people show bizarre behavior. About two third of the respondents (64.3\%) believed that mental illness is not curable. Mental illness as contagious was believed by $28.6 \%$ of the people and $40.7 \%$ believed it as hereditary disease. More than half of the respondents i.e. $51.4 \%, 63.6 \%$ and $77.1 \%$ believed mental illness is not related to physical health, mental disorders are shameful and there is low prevalence of mental illness in our country respectively. Likewise, 30\% people believed that marriage cures mental illness and $36.4 \%$ believed mental illness is caused by supernatural power. Forty one percent of respondents believed that mental illness once acquired is life-long. Similarly $45 \%$ respondents believed that there is no need of treatment for mentally ill people. Forty-nine percent of respondents believed that asylum is the place for treatment for mentally ill people. These findings are consistent with the findings of other study which showed that $39.4 \%$ of the rural respondents having belief that 
mental illness is the punishment of God for their past sin. Similarly that study also showed that $33.7 \%$ subjects in rural areas and $40 \%$ in urban areas believed mental illnesses as untreatable. ${ }^{11}$ Similarly, marriage can cure mental illness was believed by $11 \%$ of the respondents in a study. ${ }^{12}$

\section{CONCLUSION}

The knowledge about human rights of persons with mental illness is inadequate and prevalence of myths and misconceptions related to mental illness is high among the community people of selected community in Kaski district, Nepal. The continuing lack of sensitivity and awareness in the society towards the rights of mentally ill and the prevailing myths require help to create awareness through the trained health profession. The study suggests that there is an urgent need to take necessary steps to promote, protect and fulfill human rights of people with mental illness through providing appropriate care, awareness and educating the community and strengthening the legislations regarding the mental illness.

\section{Acknowledgement}

Our sincere thanks to all the participants who had given consent to be part of this study and their family members for their valuable contributions. We owe our gratitude to our B.Sc. nursing second batch 2018/19 A.D. (2074/75 B.S.) students for their tiredless job of data collection.

\section{REFERENCES}

1 World Health Organization. The World Health Report 2001. Geneva. Available at http://www. who.int/whr/2001/en/whr01_en.pdf

2 Maisel ER. The New Definition of a Mental Disorder. Psychology Today. 2013. Sussex Publishers, LLC. Retrieved from https://www. psychologytoday.com/intl/blog/rethinkingmental-health/201307/the-new-definitionmental-disorder.

3 Sreevani K. A guide to mental health and psychiatrics nursing. New Delhi: Jaypee Brothers Medical Publishers Pvt. Ltd. 2010.
4 Pathiranan DD. Perceived knowledge and attitudes pertaining to 'People with mental illness (PwMI)': A Sri Lankan Perspective. The International Journal of Indian Psychology. Oct-Dec 2016. http://www.ijip.in/Archive/ v4i1/18.01.103.20160401.pdf.

5 Corrigan PW, Watson AC. Understanding the impact of stigma on people with mental illness. World Psychiatry. 2002 Feb;1(1):16-20.

6 Sharma C, Sharma P. Essentials of Psychiatric and Mental Health Nursing ( $2^{\text {nd }}$ ed.). Kathmandu: Quality Printers Pvt Ltd.2016.

7 B Al-lela OQ, Bahari MB, Salih MRM, Al-abbassi MG, Elkalmi RM, Jamshed SQ. Factors underlying inadequate parents' awareness regarding pediatrics immunization: findings of crosssectional study in Mosul- Iraq. BMC Pediatr. 2014;14:29.

8 Santhi S. To assess the awareness of human rights among care givers caring for mentally ill admitted in psychiatric ward. Indian Journal of Psychiatric Nursing. 2009;1(1):26-8.

9 Choudhary S, Gupta S. A descriptive study to assess the knowledge regarding human rights of mentally ill among adults at selected rural areas of Moradabad with a view to develop an information booklet. International Journal of Advanced Science and Research. 2017 July;2(4):130-4.

10 Chendake M, Mohite VR, Gholap M, Naregal PM, Hiremath P. A study to assess the knowledge regarding human rights of mentally ill among post basic B. Sc. nursing students in Krishna institute of nursing sciences, Karad. Int J Health Sci Res. 2014;4(10):164-71.

11 Kishore J, Gupta A, Jiloha RC, Bantman P. Myths, beliefs and perceptions about mental disorders and health-seeking behavior in Delhi, India. Indian J Psychiatry. 2011 Oct-Dec; 53(4):324-9.

12 Gurung G. Knowledge and attitude of nurses regarding mental illness. Journal of Chitwan Medical College. 2014;4(8):40-3. 